
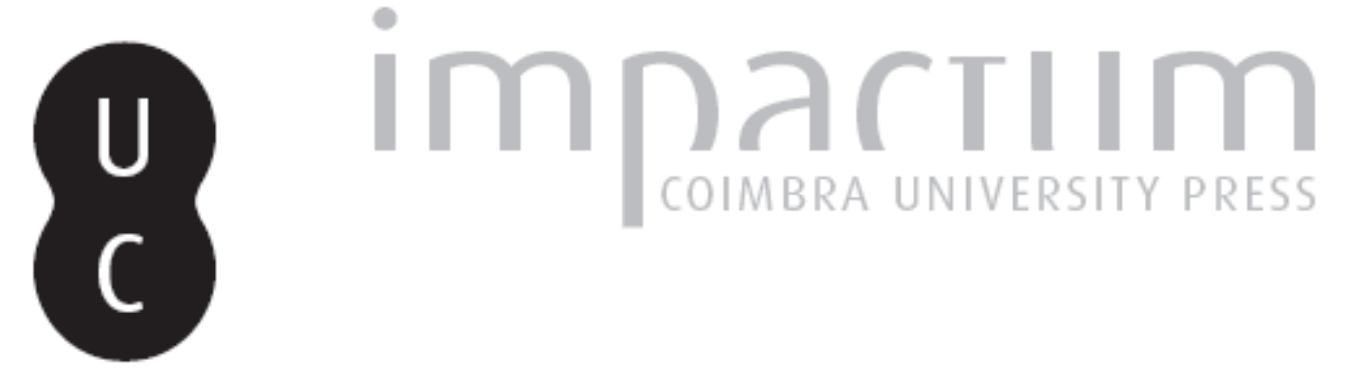

\title{
Sobre o freixo: cidade e monumento, reabilitação e projecto
}

Autor(es): Mendes, Manuel

Publicado por: Editorial do Departamento de Arquitectura

URL persistente:

URI:http://hdl.handle.net/10316.2/37408

DOI:

DOI:http://dx.doi.org/10.14195/0874-6168_1_3

Accessed : $\quad$ 26-Apr-2023 15:23:11

A navegação consulta e descarregamento dos títulos inseridos nas Bibliotecas Digitais UC Digitalis, UC Pombalina e UC Impactum, pressupõem a aceitação plena e sem reservas dos Termos e Condições de Uso destas Bibliotecas Digitais, disponíveis em https://digitalis.uc.pt/pt-pt/termos.

Conforme exposto nos referidos Termos e Condições de Uso, o descarregamento de títulos de acesso restrito requer uma licença válida de autorização devendo o utilizador aceder ao(s) documento(s) a partir de um endereço de IP da instituição detentora da supramencionada licença.

Ao utilizador é apenas permitido o descarregamento para uso pessoal, pelo que o emprego do(s) título(s) descarregado(s) para outro fim, designadamente comercial, carece de autorização do respetivo autor ou editor da obra.

Na medida em que todas as obras da UC Digitalis se encontram protegidas pelo Código do Direito de Autor e Direitos Conexos e demais legislação aplicável, toda a cópia, parcial ou total, deste documento, nos casos em que é legalmente admitida, deverá conter ou fazer-se acompanhar por este aviso.

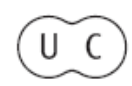




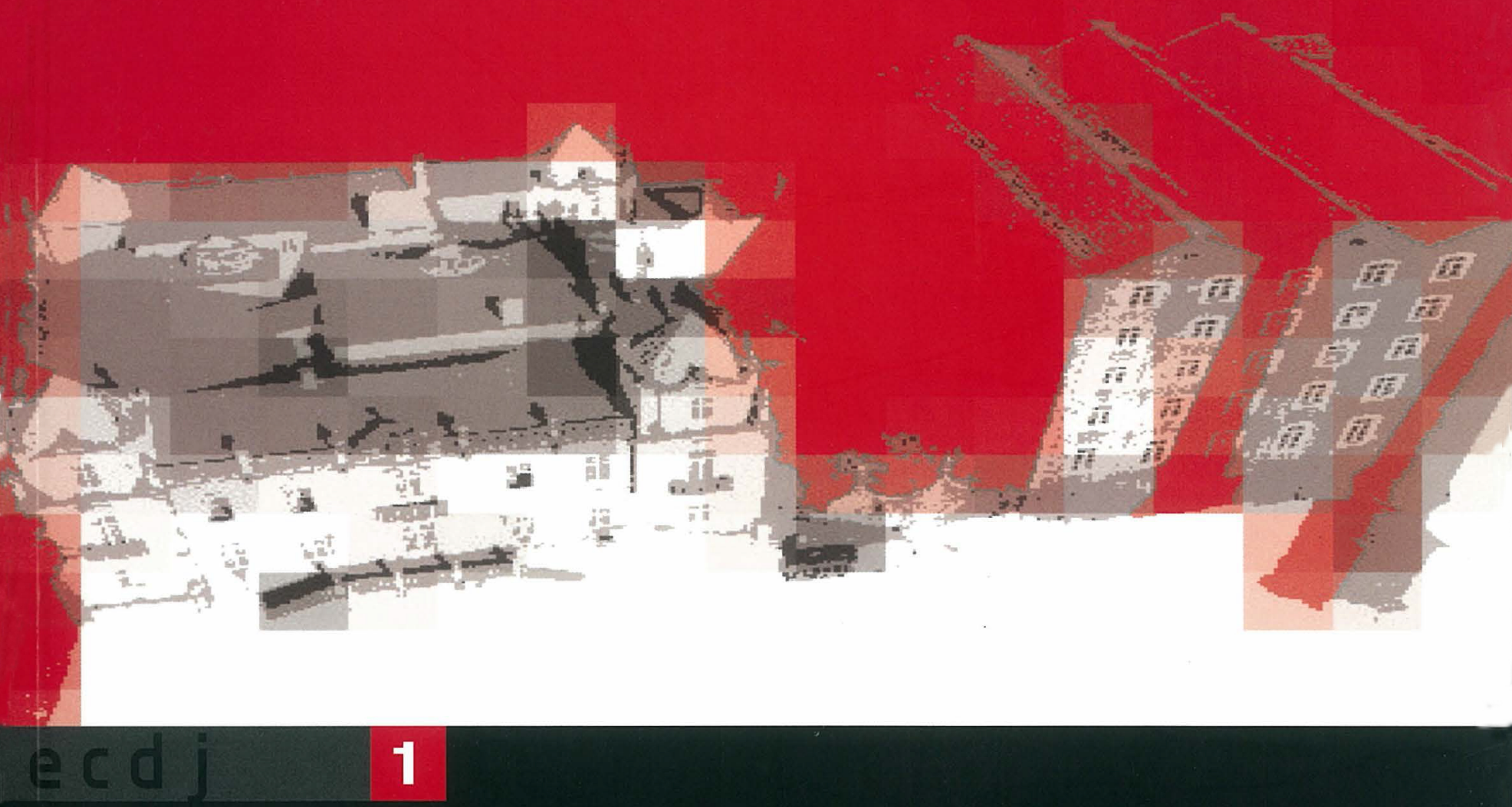

fctuc / departamento de arquitectura

\section{a polémica do Freixo Fernando Távora} alexandre alves costa | antónio olaio joão paulo rapagão | jorge figueira josé antónio bandeirinha

(2) 


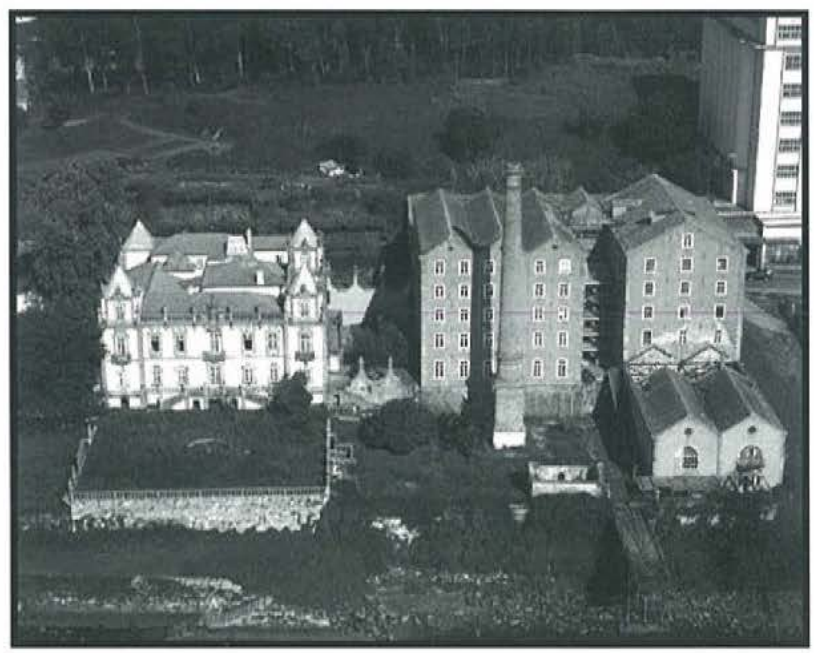


[sobre o freixo | cidade e monumento, reabilitação e projecto] Manuel Mandes

\footnotetext{
"Que impulso contraditório é esse que determina a vontade de deter a passagem da temporalidade no objecto artistico, quando, simultaneamente a origem da valorização está na sua natureza histórica?"

J. Hernandez León, La Naturaleza de lo Antigo y el Impulso Restaurador
}

1 | Sobre as formas do construído, sobre o processo de dar uma forma visual à cidade e a possibilidade de a modificar, ou sobre o destino dos testemunhos históricos da cidade, se se apresta o legado da modificação ensaiado pelo pensamento moderno logo se agita o impulso da euforia patrimonialista que não é exactamente a mesma coisa que o restauro ou a reabilitação como técnicas de intervenção no construído (a arquitectura e a cidade). Na conservação do existente, se se problematiza a operatividade do "valor de evocação", do "valor histórico", do "valor artístico", do "valor de antiguidade", como percepção moderna da natureza do antigo, como esforço vital de manifestação cultural e disciplinar modernas, logo acena a sedução da diferença e da mudança operadas por um processo orientado por pautas produtivistas distraídas com a evasão mumificante do antigo, com a reabilitação desfocada para um restauracionismo economicista e festivaleiro, os quais são tudo menos atenção à identidade do antigo.

> Daí que, no relacionamento com a cidade herdada aceite como bem histórico-artístico, se se insiste na ideia de musealização da cidade - experiência de estima cultural por testemunhos históricos da cidade, solidária com um ideal de instrução pública, de sensibilidade e civismo, de "expressão vital de identidade comunitária na sua história e no seu destino", logo se apresta a ideia de museificação da cidade - experiência de fervor estupefaciente, reproduzida/ desenvolvida por "uma economia de esforço perceptivo - economia funcionalista, alimentada por uma selecção de valores operados pela cultura mediática e orientados para o consumo"(V. Escolano).

> Toda a reflexăo autocrítica que arquitectura e urbanística operaram nas últimas quatro décadas revogaram de vez as certezas de um modernismo anti-historicista ou de maneira: a reconsideração da cidade histórica, a relação plano e projecto, o conceito de intervenção, o problema do significado em arquitectura. 
Produziu um novo campo de elaboração, uma estratégia de escuta, de reavaliação da individualidade dos lugares - de ideia do projecto como uma modalidade da modificação bem temperada sobre o qual agem categorias diversas sob o índice comum de assunção positiva do existente. Por aĺ, a arquitectura recuperou a cidade com a missão especifica de configurar a sua forma física e, simultaneamente e em relação com a história, a cidade converteu-se em fonte da arquitectura, facto em torno do qual articula a sua própria fundação disciplinar. Por aí, a disciplina e o projecto renunciaram à prejudicial contraposição da racionalidade do novo à organicidade do antigo.

> Na perspectiva, talvez se possa enunciar que "a natureza do antigo resulta relativizada pela sua própria história, pela qualidade da sua presença na memória colectiva. A autoconsciência do indivíduo histórico, a consciência moderna, rompeu a dimensão mítica do antigo como ideal inalcansável e, ao mesmo tempo, modelo de referência.

> É, portanto, o tempo o parâmetro determinante da qualidade de determinados objectos, da sua natureza evocadora ou da sua capacidade exemplificadora nos processos criativos. Assim é, não só porque a História foi modificando a valorização do antigo, mas também porque a própria modernidade assinalou uma subtil linha de demarcação quanto à disponibilidade do monumento antigo"(J. León).

2 | Pela classificação de "património cultural da humanidade" atribuida ao seu núcleo de fundação - designação imprecisa mas que assim mesmo preferirei à de centro histórico - o Porto acrescenta o aceno de lugar do mundo ao lugar que é o seu nome do lugar. Um aceno, diga-se, à permanência do antigo, ancoradouro da sua imagem de cidade, de comunidade. A permanência que não celebração do antigo figurativo assim feito indústria evocativa da nostalgia, mas, bem ao contrário, a permanência como estabilidade, valor do antigo a recuperar como e pela circulação de cultura no presente histórico.

> Daí que, por exemplo, à pergunta "existe um centro histórico?" devamos responder negativamente, mas só porque existem tantas estruturas históricas quantas saibamos / queiramos conhecer, valorizar, prolongar. " Sabemos que a velha questão dos centros históricos em sentido estrito perdeu a sua força propulsora, mas que muitos problemas e temas por si agitados permanecem e necessitam 
de uma reflexão actualizada da cidade histórica e do papel da história na cidade contemporânea e dos modos de cuidar a qualidade mediante formas apropriadas de análise-plano-projecto"(A. Terranova).

> Dito isto, tenho por adquirido que projectar é antes de mais conhecer, conhecer para intervir. Conhecer para intervir acreditando que se possa modificar, qualificando, a realidade da qual se veio, também, parcialmente, a conhecer os mecanismos de formação.

No projecto, enunciar-observar-desenhar são expressão criativa em sistema aberto no qual e pelo qual informam-enformam a modificação para transformar.

> Dito isto, é preciso não jogar fora simplesmente o passado e toda a sua história: o que é preciso é considerar o passado como presente histórico. "Na prática, não existe o passado. O que existe ainda hoje e não morreu é o presente histórico. O que você tem que salvar - aliás, salvar não, preservar - são certas características típicas de um tempo que pertence ainda à humanidade". "Mas, se a gente acreditar que tudo o que é velho deve ser conservado, a cidade vira um museu de cacarecos. Num trabalho de restauração arquitectónica é preciso criar e fazer uma selecção rigorosa do passado". "O resultado é o que chamamos de presente histórico".

> Frente ao presente histórico, a nossa tarefa é forjar um outro presente, "verdadeiro", e para isso é necessário não um conhecimento profundo de especialista, mas uma capacidade de entender historicamente o passado, saber distinguir o que irá servir para novas situações de hoje que se apresentem(L. Bardi).

3 | Creio que foi a Augusto Santos Silva que ouvi um dia expor que "a esquerda não deve ser iluminista", e, logo de seguida, "mas uma coisa é abandonar o iluminismo, e outra coisa é abandonar o ideal de esclarecimento". Sabe-se que o corpo de um tal ideal não nasce feito, ao contrário, é coisa de construção lenta, e uma responsabilidade colectiva.

> Assim mesmo, contra a cegueira iluminada dos artistas-de-"este Porto tem direitos de autor"(Visâo), tenho como oportuno que faz tempo "chegou o momento em que a liberdade não tem qualquer outro significado senão o de ser vivida humildemente. É mais uma qualidade do homem, e cada vez menos o seu privilégio"(A, Bessa Luis). 
Talvez por isso, o seu "Porto, uma cidade para descobrir" não deixe de parecer, progressivamente, um projecto de arqueologia surrealista ou esclarecimento de abandono metafísico em errância duvidosa.

> A ocupação do espaço por mais promíscua que seja é eminentemente um acto ético no qual a escala não é convenção de uma qualquer representação, antes uma convicção. Deste modo se torna cada vez mais difícil suportar a palavra tosca, por vezes a grosseria primária, com que algumas personalidades, sem esclarecer, fazem circular como referendo de resultado pré-determinado os aspectos mais mediáticos do que se convenciona designar valorativamente de "património", e que talvez pudéssemos designar tão só de bens históricos - "bens históricos são aqueles elementos materiais que conservámos de pretéritos presentes. Bens cujo valor é uma qualidade mutável, determinada conforme a ideia de interpretação que evoluciona com a própria história. A sua protecção não seria senão o reflexo dessa ideia interpretativa mutável"( $($. Escolano).

Tenha-se presente a polémica provocada pelos estudos coordenados pelo arquitecto Fernando Távora para a última tentativa de recuperação do Palácio do Freixo, monumento nacional. Por partes.

a

Para Fernando Távora um edifício sem fundações, tal como árvore sem raízes, não existe: "mas as fundações do edifício ou de uma cidade têm que ser mais profundas, mais significativas do que as suas fundações físicas; embora estranho, um novo edifício deve manter um diálogo com os seus vizinhos ou com o seu local". Talvez por isso, diga amiúde que "muita da nossa arquitectura, em sentido lato, esbraceja para vencer mas não chega: perde referência, perde gravidade, não chega ao eixo da terra, não chega mesmo ao coração do homem porque se entretem na dolorosa e fácil aventura da forma pela forma, pelo êxito da imagem, pela eloquência balofa, pelo decorativo contra a estrutura, pela falsidade contra a inteligência".

> Na conciliação hábil entre composição e linguagem, Fernando Távora fez por ultrapassar o que ora sugere incapacidade, inabilidade, desinteresse em ser moderno, ora impossibilidade, inoportunidade, 
ineficácia do ser moderno. Fernando Távora desenha ao ritmo da memória: a arquitectura é recuperar e construir. Não existem problemas de património existem problemas de arquitectura e de cidade e, portanto, numa perspectiva disciplinar, existem problemas de desenho, de projecto arquitectónico, de parte de cidade, de cidade ou urbano.

b

Em Fernando Távora, o projectar sempre se apresenta como experiência de desenho que, restaurando/repondo/reabilitando, considera/interpreta as regras do existente pela compreensão propositiva das convençōes formais que o regem, à luz duma sensibilidade artística/estética da contemporaneidade. É por aqui que a sua postura se apresenta mais moderna - eventualmente, pós-moderna - que a dos seus críticos, nomeadamente, aqueles que tudo conservariam sem nunca se Ihes colocar como campo operativo do desenho o restauro, mas unicamente a reabilitação. Este é o refúgio paradoxal de um moderno que, por pudor ou instinto de sobrevivência, se permite conservar burocrática ou nostalgicamente, se permite deformar o lugar sem se territorializar no lugar de que se quis referência transformadora.

\section{c}

Já que o que existe não é estático e imutável, o seu conceito de projecto coloca a intervenção em bens históricos sem obedecer a apriorismos de salvaguarda, mas à avaliação do problema a intervir. > Assim, no Freixo, o que está em causa não se trata de um problema de gosto, restício aristocrático, passadismo anacrónico, visão redutora da ideia de monumento, antes conceito de projecto e de História, de teoria de intervenção arquitectónica e de postura disciplinar; ou tão só, de oportunidade para "deixar o edifício falar"(I. Solà-Morales). O seu conceito de desenho argumenta-se na leitura propositiva da história do lugar, na compreensão crítica da dimensão espacial - forma, escala, significado - do sítio físico da intervenção; e por isso, o impulso restaurador e a intervenção moderna se reconhecem como espaço de modificação do monumento, gerado a partir de uma estância estética e contaminado por sensibilidade contemporânea. O seu conceito de intervenção evolui na interpretação crítica do significado artísticomonumental do existente - palácio, moagem, palácio e moagem -, do 
programa razão da intervenção, e do quadro de relações que entre si se geram. O problema de intervir em arquitecturas pretéritas é fundamentalmente um problema de arquitectura, de arquitectura do presente e não da arbitrariedade de uma interpretação neutral dos critérios ou da experiência histórica no âmbito da intervenção.

\section{d}

O lugar do Freixo fez-se numa morfogénese de choques nos destinos de uso e formas da ocupação, nas convenções da composição do assentamento e da arquitectura: quinta de recreio e palácio (condição terra), palácio paredes meias com a antiga moagem Harmonia (condição rio), núcleo fabril. Entrada oriental da cidade, é uma área urbana da periferia portuense em situação de parcial abandono, anotada desvalorativamente na sua caoticidade e indefinição urbana: descontinuidade da aglomeração; consolidação instável e larga indefinição, fragmentada e desconexa; espaço público, estrada e caminhos numa rede de circulações mais ou menos dolorosas, fraca acessibilidade, pouco dócil a paragens, encontros, contemplações. Pese o potencial paisagístico e a presença de bens materiais de interesse histórico-artístico, foi objecto de vária iniciativas de reabilitação ou destino, amálgama de diferentes categorias de interpretação histórica, critérios de restauro-reposição-recuperaçãoreconstruçăo, adiados ou suspensos, parcialmente realizados.

> A sua condição de eterna indefinição tornou-a zona de interesses em trânsito - imobiliários, turísticos, culturais, representação; fez atrair programas para novas ocupações de propósitos pouco considerados, usos ocasionais, indiferenciados, atraídos pelas modas estéticasculturais do vazio e lixos urbanos. Propagandas de ocasião numa casuística à justa medida do carreirismo politiqueiro, permitiram o depósito de projectos pouco considerados de interesse presumidamente cultural, que o tempo foi instalando como grupos de pressão geridos por interesses nem sempre muito culturais.

e

Os estudos agora elaborados, ainda em fase instrutória para a estratégia do desenho e decisão política, desenvolveram-se numa postura que, pela primeira vez, abordou a salvaguarda do monumento pela compreensão de uma proposta de intervenção para o lugar do Freixo reabilitando-o como parte de cidade para a cidade - rio, 
margem, encosta, rede viária, edifícios, espaço público/jardins. O seu autor não é um arquitecto moderno, mas pratica um "culto moderno dos monumentos" para uma postura de projecto que faz evoluir por critérios de renovação da memória. Assim, no conceito que propõe para dar uma imagem de cidade ao lugar do Freixo, não surpreende o vínculo de solidariedade monumento-lugar, edifício-sítio, expresso na extensão/continuidade da ordem compositiva do palácio ao território próximo e a demolição/reposição do edificio fabril anexo, noutro local.

> O brado "eliminar a Harmonia é um atentado ao património e implica perder toda a memória que Ihe está associada"(J. Lopes Cordeiro) não se fez esperar, como se para a utilidade da memória e a atribuída singularidade do edifício industrial não existam outros processos/técnicas de salvaguarda/protecção que não o da sua invulnerabilidade física; ou como se a reabilitação do edifício industrial para uma qualificada instalação de um museu da Ciência e Indústria não coloque, sem hesitação, a desbarato essa mesma invulnerabilidade, por mais sérios que sejam os critérios para tal reabilitação.

> "Recupere a composição palaciana com a construção de um túnel sobre o edifício da moagem"(N. Portas), "todas as épocas informam a história da cidade", "desenhar uma fábrica que surge como continuidade da composição do Palácio", "porque não desloca o palácio?", "o resto do notável projecto para a encosta do Freixo", "o palácio é mais industrial que barroco", "foi o palácio que proporcionou a existência da indústria naquele local"(J. Rapagăo), o palácio não é dama barroca-oca e cheia de ro-cocós que precise livrar-se de más companhias"(M. Pessanha) são grotescas manifestações de cidadania, para não menos grotescas manipulações política, cultural, disciplinar, profissional; olhares de insensibilidade histórica, artística e/ou técnica de alguns, eventualmente os mesmos, que se congratulam, activa ou silenciosamente, com a razia despudorada que se pratica na cidade histórica e, mais particularmente, no "Porto, cidade património" em nome do que chamam desenvolvimento ou criatividade, mestiçagem ou contemporaneidade, salvaguarda do património ou salvaguarda da imagem urbana.

> Tenho como assente que a recuperação do passado a partir da nossa contemporaneidade deve entender-se como reconstrução de algo que 
inclusivamente pode não ter existido como tal, da memória apenas desvelada pelos nossos actos. O projecto redefinirá outra ideia de tempo, porquanto é encruzilhada onde confluem memória, história e contemporaneidade.

\section{f}

Ao aceitar-se (F.Távora) Como revisão do primeiro esboço de projecto, a proposta de deslocação do edifício da moagem significa um recuo comprometedor da solução de princípio - a eliminação do edifício da moagem, acompanhada por eventual reabilitação/integração da estrutura de ferro ou outras partes ou materiais do edifício da antiga moagem na construção de edifício de raiz na área do Freixo ou noutro sítio da cidade. E o recuo não é aqui puro artifício teórico, antes questão ontológica decisiva. A "transplantação para sul-poente", de trezentos metros, do edificio da moagem Harmonia - desvio correctivo da implantação original, eventualmente anacrónica, brutal - sugere, no seu significado, algo de gesto messiânico, representação reparadora da história (ou talvez melhor, das representações que dela fazemos), esforço purificador do monumento que é o palácio e não o é o sinal da conflitualidade histórica fixada pela associação física palácio+moagem.

4| Traçada como está a orientação política para o problema, apenas resta dignificar toda a reserva ao unanimismo galante de "Moagens vencem Palácio do Freixo"(Expresso). O título funciona mediaticamente, tanto quanto sintetiza da elevada concentração de estímulos contraditórios, leituras equívocas ou abusos discursivos, da colisão/sobreposição de alianças/destinos contraditórios; tanto quanto oculta por entre pressões e projectos de grupos imobiliários ou negócios de obras públicas, acertos partidários ou ajustes-concorrências particulares entre bandas políticas do círculo autárquico portuense, afrontamento de tendências/grupos profissionais ou empolamentos para ficções de acicate geracional; tanto quanto dissolve entre despudores de ignorância à deriva, $\mathrm{e}$ outras derivas para acertos de "escola" locais ou outras causas imaginárias para atrevimentos sem caução libertária.

> Em resumo, sombras ou insistências, passagens ou alinhamentos que na imensidão de interesses que agitam não pretendem - se alguma 
vez o pretenderam - problematizar cultural e disciplinarmente o conceito de intervenção no lugar em questão; e/ou não pretendem compreender historicamente o problema arquitectónico - as relações entre o tempo e as conformações do espaço arquitectónico e urbano correctamente equacionado na postura teórica de Fernando Távora, postura teórica independente da confirmação colectiva que possa transmitir a solução projectual que desenvolveu. Persistência reveladora da situação portuguesa, o que uma vez mais se Ihe seguiu, retrata pálida ou desconcertante imagem de cidadania disciplinar da arquitectura: com o seu conhecimento ou a sua renúncia se pratica o mais rasteiro dos serviços à comunidade - sinais para uma geografia sem identidade, orientações para uma identidade sem paisagem.

s Colocado como está o problema, a solução de compromisso que é trasladação da Harmonia expõe, numa evidência quase púdica, a conciliação de contraditórios que é um dos atributos mais persistentes e mais estruturantes do fazer arquitectónico de Fernando Távora. Complementarmente, pelo que deforma, serve à denúncia ferida do modelo teórico que de forma grave, o seu autor tão sabiamente faz circular na sua obra construída e escrita. Por mais duro que seja afirmá-lo, a proposta de trasladação da fábrica de moagem desertifica qualquer espaço para acto de solidariedade com o seu autor; solidariedade tão justificável quanto o iluminismo cego entontece o ideal do esclarecimento. Ao caso, o apelo naquele sentido, resultaria na mais magoada, na mais deslocada e vazia forma de solidariedade: a empatia personalista.

> Arrumado como está o problema, lembra-me que "a multidão tem sempre razão quando se trata de sobreviver; mas quando se trata de viver, é o indivíduo que tem que argumentar com o instinto e convencer-se a escolher. A beleza das praias não pode ser um direito à grosseria do gosto e à inaptidão das empresas turisticas. É um património, não é um domínio. Porque não reparam no vandalismo legal que por toda a parte se pratica? Somos nós tão ecdj $58 \cdot 33$ ricos, que possamos construir com inépcia aquilo que se decida ser corrigido com grandeza? Ou somos tão pobres, que a cultura não deva saber o que se faz por caciquismo e anarquia?"(A. Bessa Luis). 